\title{
MOLECULAR CHARACTERIZATION OF TRICHOMONADS FROM FECES OF DOGS WITH DIARRHEA
}

\author{
Jody L. Gookin, Adam J. Birkenheuer ${ }^{\star}$, Victoria St. John, Michelle Spector†, and Michael G. Levy \\ Department of Molecular Biomedical Sciences, College of Veterinary Medicine, North Carolina State University, Raleigh, North Carolina 27606. \\ e-mail: jody-gookin@ncsu.edu
}

\begin{abstract}
Trichomonads are occasionally observed in the feces of dogs with diarrhea. On the basis of superficial morphological appearance, these infections have been attributed to opportunistic overgrowth of the commensal, Pentatrichomonas hominis. However, molecular characterization of canine trichomonads has never been reported. This study was performed to determine, by means of rRNA gene sequence analysis, the identity of trichomonads observed in feces from dogs with diarrhea. Total DNA was isolated from fecal samples obtained from a 3-mo-old mixed breed dog and litter of German Shepherd puppies having profuse liquid diarrhea containing numerous trichomonads. Total DNA was subject to PCR amplification of partial 18S rRNA gene or 5.8S, ITS1, ITS2, and partial $18 \mathrm{~S}$ and $28 \mathrm{~S}$ rRNA genes using species-specific and universal primers, respectively. Products of 642 and 1864 base-pair length were amplified and cloned. On the basis of rRNA gene sequence, the trichomonads observed in the single dog and the litter of puppies shared $100 \%$ identity with Tritrichomonas foetus and P. hominis, respectively. The present study is the first to establish the molecular identity of trichomonads infecting dogs with diarrhea. These studies validate the longstanding assumption that canine trichomoniasis may be attributed to $P$. hominis. Importantly, these studies additionally recognize that canine trichomoniasis may also be caused by infection with $T$. foetus.
\end{abstract}

Trichomonads are obligate protozoan symbionts found in vertebrates and are considered to be among the most primitive eukaryotic organisms. They are characterized morphologically by multiple anterior flagella and a single recurrent flagellum that functions as an undulating membrane. Trophozoites reproduce by binary fission and undergo direct transmission from host to host without formation of environmentally stable cysts (Felleisen, 1999).

Both commensal and pathogenic species of trichomonads exist. Tritrichomonas foetus is recognized as an important venereal pathogen of naturally bred cattle in which the organism is transmitted from the prepuce of the bull to the reproductive tract of the cow where infection leads to infertility and abortion (BonDurant, 1997). In domestic cats, T. foetus is transmitted by the fecal-oral route, resulting in infection of the colonic lumen and chronic large-bowel diarrhea (BonDurant, 1997; Gookin et al., 1999; Gookin et al., 2001; Levy et al., 2003; Gookin et al., 2004). In contrast to $T$. foetus, Pentatrichomonas hominis inhabits the large intestine of a number of mammalian hosts and is considered to be a commensal (Wenrich, 1944).

Large numbers of trichomonads are occasionally seen in the feces of young dogs with diarrhea (Simic, 1932a; Bruce, 1941; O'Donnell, 1954; Burrows and Lillis, 1967; Niiyama et al., 1972; Narayana, 1976; Turnwald et al., 1988). Most current veterinary textbooks attribute these infections to opportunistic overgrowth of P. hominis (Guilford and Strombeck, 1996; Barr, 1998; Jergens and Willard, 2000); however, molecular characterization of the trichomonads observed in feces from dogs with diarrhea has never been reported. This study was performed to determine, by means of rRNA gene sequence analysis, the identity of trichomonads observed in feces obtained from dogs with diarrhea.

Received 22 September 2004; revised 13 December 2004; accepted 14 December 2004.

* Clinical Sciences, College of Veterinary Medicine, North Carolina State University, Raleigh, North Carolina 27606.

$\dagger$ Fred Hutchinson Cancer Research Center, Seattle, Washington 98109.

$\ddagger$ Department of Farm Animal Health and Resource Medicine, College of Veterinary Medicine, North Carolina State University, Raleigh, North Carolina 27606.

\section{MATERIALS AND METHODS}

\section{DNA isolation}

Total DNA was isolated from voided fecal samples (180-220 mg) using a commercial kit (QIAamp DNA stool mini kit; Qiagen, Valencia, California) in accordance with manufacturer instructions and with modification to optimize elimination of PCR inhibitors as previously described (Gookin et al., 2002).

\section{PCR amplification of $T$. foetus rRNA genes}

DNA extracted from feces was first subject to single-tube nested PCR using T. foetus-specific primers designed to amplify a 208-base-pair sequence of the internal transcribed spacer region (ITS) 1 and $5.8 \mathrm{~S}$ rRNA gene. Conditions for PCR were as follows: $100 \mu$ l reaction volume of PCR buffer II containing 1.25 U of Perkin-Elmer Amplitaq Gold DNA polymerase (Applied Biosystems, Foster City, California), $5 \mathrm{mM}$ $\mathrm{MgCl}_{2}, 1.25 \mathrm{pmol}$ each of primers TFR3 (5'-CGGGTCTTC CTATATG AGA CAGAACC- $3^{\prime}$ ) and TFR4 (5'-CCTGCCGTTGGATCAGTTTC GTTAA-3'), 25 pmol each of primers TFITS-F (5'-CTGCCGTTGGA TCAGTTTCG-3') and TFITS-R (5'-GCAATGTGCATTCAAAGATC G-3'), $200 \mu \mathrm{M}$ each of dNTP, $10 \mu \mathrm{g}$ of BSA, and $5 \mu 1$ of DNA template. Amplification was performed in an iCycler with the following profile: Initial denaturation at $95 \mathrm{C}$ for $5 \mathrm{~min}$, denaturation at $95 \mathrm{C}$ for $30 \mathrm{sec}$, annealing and extension at $72 \mathrm{C}$ for 1 min for 30 cycles; denaturation at $95 \mathrm{C}$ for $30 \mathrm{sec}$, annealing at $57 \mathrm{C}$ for $30 \mathrm{sec}$, extension at $72 \mathrm{C}$ for $30 \mathrm{sec}$ for 50 cycles, and a final extension at $72 \mathrm{C}$ for $5 \mathrm{~min}$.

DNA extracted from feces was also subject to PCR using $T$. foetusspecific primers designed to amplify a 642-base-pair sequence of the 18S rRNA gene. Conditions for PCR were as follows: $100 \mu 1$ reaction volume of PCR buffer II containing 1.25 U of Perkin-Elmer Amplitaq Gold DNA polymerase, $5 \mathrm{mM} \mathrm{MgCl}, 25$ pmol each of primers $499 \mathrm{~F}$ (5'-GCTCGTAGTCAGAACTGC- $\left.3^{\prime}\right)$ and 1140R (5'-CCCAATTAGA ACTCTATCTC-3'), $200 \mu \mathrm{M}$ each of dNTP, $10 \mu \mathrm{g}$ of BSA, and $5 \mu \mathrm{l}$ of DNA template. Amplification was performed in an iCycler with the following profile: Initial denaturation at $95 \mathrm{C}$ for $5 \mathrm{~min}$, denaturation at $95 \mathrm{C}$ for $1 \mathrm{~min}$, annealing at $60.1 \mathrm{C}$ for $1 \mathrm{~min}$, extension at $72 \mathrm{C}$ for $2 \mathrm{~min}$ for 35 cycles, and a final extension at $72 \mathrm{C}$ for $5 \mathrm{~min}$. Amplicons were visualized by UV after electrophoresis in a $1.5 \%$ agarose gel containing ethidium bromide. Reaction products were purified (QIAquick PCR purification kit; Qiagen) and sequenced in triplicate by a commercial laboratory.

\section{rRNA gene amplification of $\boldsymbol{P}$. hominis}

A 1,864-base-pair sequence of the RNA operon including the 18S, $5.8 \mathrm{~S}$, ITS1, ITS2, and partial 28S rRNA genes was amplified from total DNA extracted from canine feces using primers capable of amplifying both $T$. foetus and $P$. hominis rRNA genes as previously described (Levy et al., 2003). Conditions for PCR were as follows: $100 \mu 1$ reaction volume of PCR buffer II containing 1.25 U of Perkin-Elmer Amplitaq 


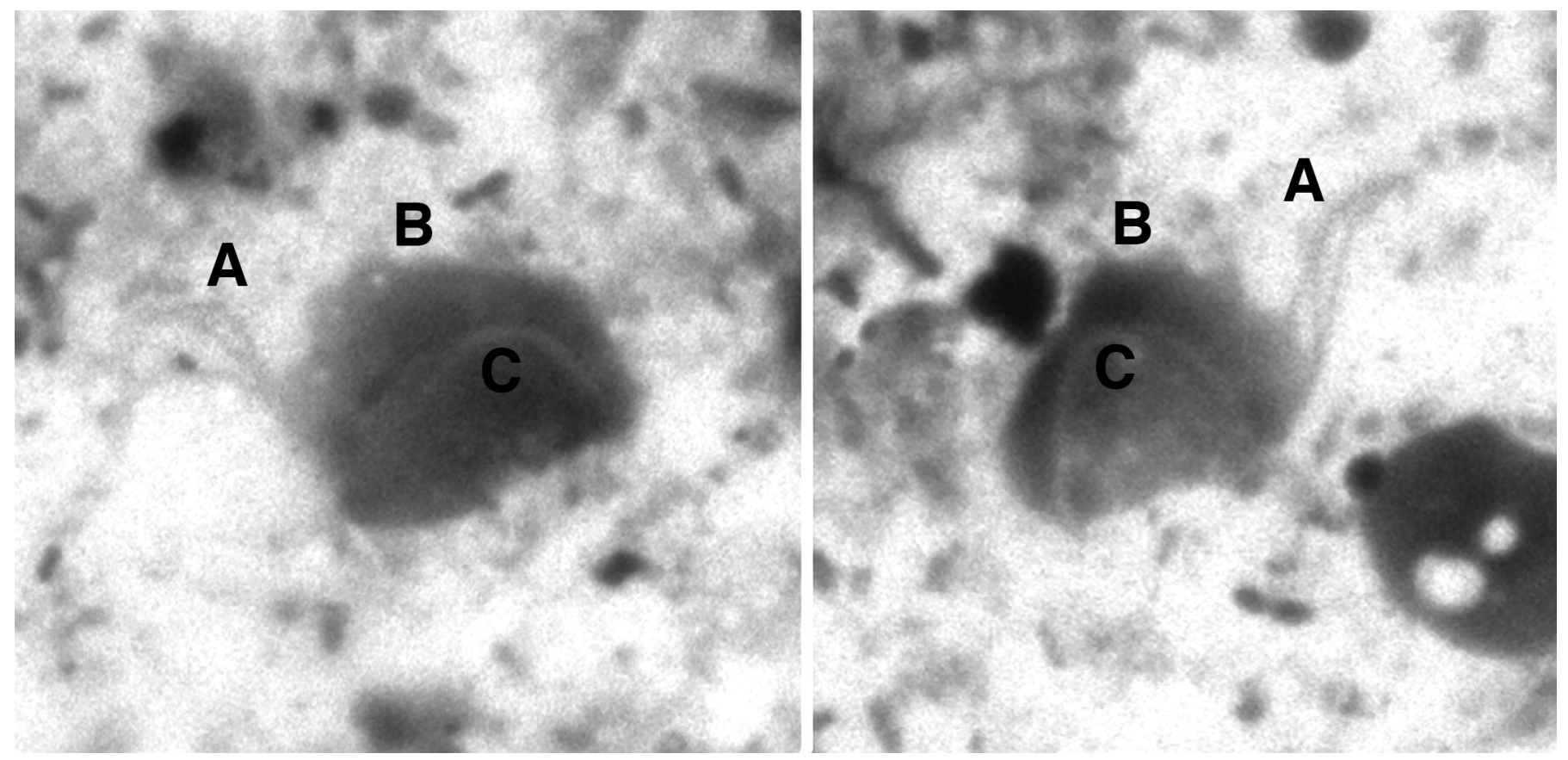

FIGURE 1. Direct fecal smear, stained with Diff Quick, from a 3-mo-old dog with liquid diarrhea. Two different trichomonads are shown. All trichomonads identified had 3 anterior flagella (A). Undulating membrane (B) and axostyle (C) can also be seen.

Gold DNA polymerase, $2.5 \mathrm{mM} \mathrm{MgCl} 2,25$ pmol each of primers (forward 5'-CCATGCAAGTGTTA GTTC-3') and (reverse 5'-TAGTTTC TTTTCCTCCGC-3'), $200 \mu \mathrm{M}$ each of dNTP, $10 \mu \mathrm{g}$ of BSA, and $5 \mu \mathrm{l}$ of DNA template. Amplification was performed in an iCycler with the following profile: Initial denaturation at $95 \mathrm{C}$ for $5 \mathrm{~min}$, denaturation at $95 \mathrm{C}$ for $1 \mathrm{~min}$, annealing at $60.1 \mathrm{C}$ for $1 \mathrm{~min}$, extension at $72 \mathrm{C}$ for $2 \mathrm{~min}$ for 50 cycles, and a final extension at $72 \mathrm{C}$ for $5 \mathrm{~min}$. Amplicons were visualized by UV after electrophoresis in a $1.5 \%$ agarose gel containing ethidium bromide. Reaction products were purified by gel extraction (QIAquick gel extraction kit; Qiagen). The PCR product was cloned into a plasmid vector $\left(\mathrm{pCR}^{\circledR}\right.$ 2.1-TOPO ${ }^{\circledR}$; Invitrogen, Carlsbad, California) and used to transform Escherichia coli (One Shot Mach1 $\mathrm{T}^{\mathrm{R}}$; Invitrogen) following the protocol of the supplier. Recombinants were selected by blue-white colony screening and plasmid DNA from at least 3 clones was isolated (QIAprep Spin Miniprep Kit; Qiagen). Plasmids were analyzed for inserts by PCR. Recombinant plasmid DNA was sequenced in triplicate by a commercial laboratory using primers M13R (5'-CAGGAAACAGCTATGAC-3') and M13F (5'-GTAAAAC GACGGCCAG- $3^{\prime}$ ). An internal sequencing primer, 515F (5'-GTGCC AGCAGCCGCGGTAA-3') was used for full-length 18S rRNA gene sequencing.

\section{Sequence analysis}

Nucleotide sequences were analyzed and compared to existing GenBank sequences using DNASTAR (DNASTAR Inc., Madison, Wisconsin) and ClustalW multiple-sequence alignment programs. The canine trichomonad sequences determined in this study were assigned GenBank numbers AY754332 and AY758392.

\section{RESULTS}

Feces were obtained from a 3-mo-old purpose-bred female mixed-breed $\operatorname{dog}(3.5 \mathrm{~kg})$ born in a research colony. The pup was described as a "poor doer" and had clinical signs of profuse watery diarrhea, dehydration, weight loss, and lethargy. Diagnostic evaluation included a complete blood cell count, serum biochemical analysis, and fecal analysis including flotation, Gram stain, and IFA testing for Cryptosporidium sp. and Giardia sp. Abnormalities identified included a mild, nonregenera- tive anemia (hematocrit 32.9\%; reference range, 37-55\%), neu-

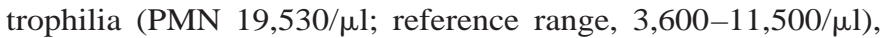
hyponatremia (134 $\mathrm{mEq} / \mathrm{L}$; reference range, $140-158 \mathrm{mEq} / \mathrm{L})$, and panhypoproteinemia (albumin $1.8 \mathrm{~g} / \mathrm{dl}$; reference range, 2.3-4.0 g/dl; globulin $1.7 \mathrm{~g} / \mathrm{dl}$; reference range, $2.7-4.4 \mathrm{~g} / \mathrm{dl}$ ). Feces were positive for Giardia sp. by IFA. The dog was treated with appropriate oral doses of fenbendazole, sulfadimethoxine, amoxicillin-clavulanate, and tylosin and fluids were given subcutaneously. After $2 \mathrm{wk}$ of therapy, the diarrhea remained severe and watery. Feces were submitted for flotation, Gram and Wright's stains, IFA for Cryptosporidium sp. and Giardia sp., and examination by wet mount. Feces contained abundant, highly motile trichomonads (Fig. 1), numerous Clostridium sp. spores, low numbers of inflammatory cells, and were negative for Giardia sp. and Cryptosporidium sp. antigen. Treatment with metronidazole (50 mg/kg PO q $24 \mathrm{hr}$ for 14 days) and amoxicillin was initiated and fecal samples from the affected pup (3 samples) and fostering bitch ( 2 samples) were sent to the authors' laboratory for analysis by PCR.

A 208-base-pair product was amplified from DNA extracted from the pup's feces using a single-tube nested PCR with $T$. foetus-specific primers (Gookin et al., 2002). Based on a comparison of each of 208 base-pair positions, the sequence shared $100 \%$ identity with the ITS 1 and 5.8S rRNA gene sequence of T. foetus (AF466749-51, AY055799, M81842). Amplicons were detected in samples obtained on day 3 and day 14 of treatment with metronidazole. Amplicons were not detected after PCR when either DNA extracted from a fecal sample obtained from the fostering bitch or from control samples that did not contain DNA were used as template for the reaction. To confirm that the feces contained $T$. foetus and that we had not amplified a laboratory contaminant, primer sequences were designed to amplify a 642-base-pair sequence of the $T$. foetus $18 \mathrm{~S}$ 


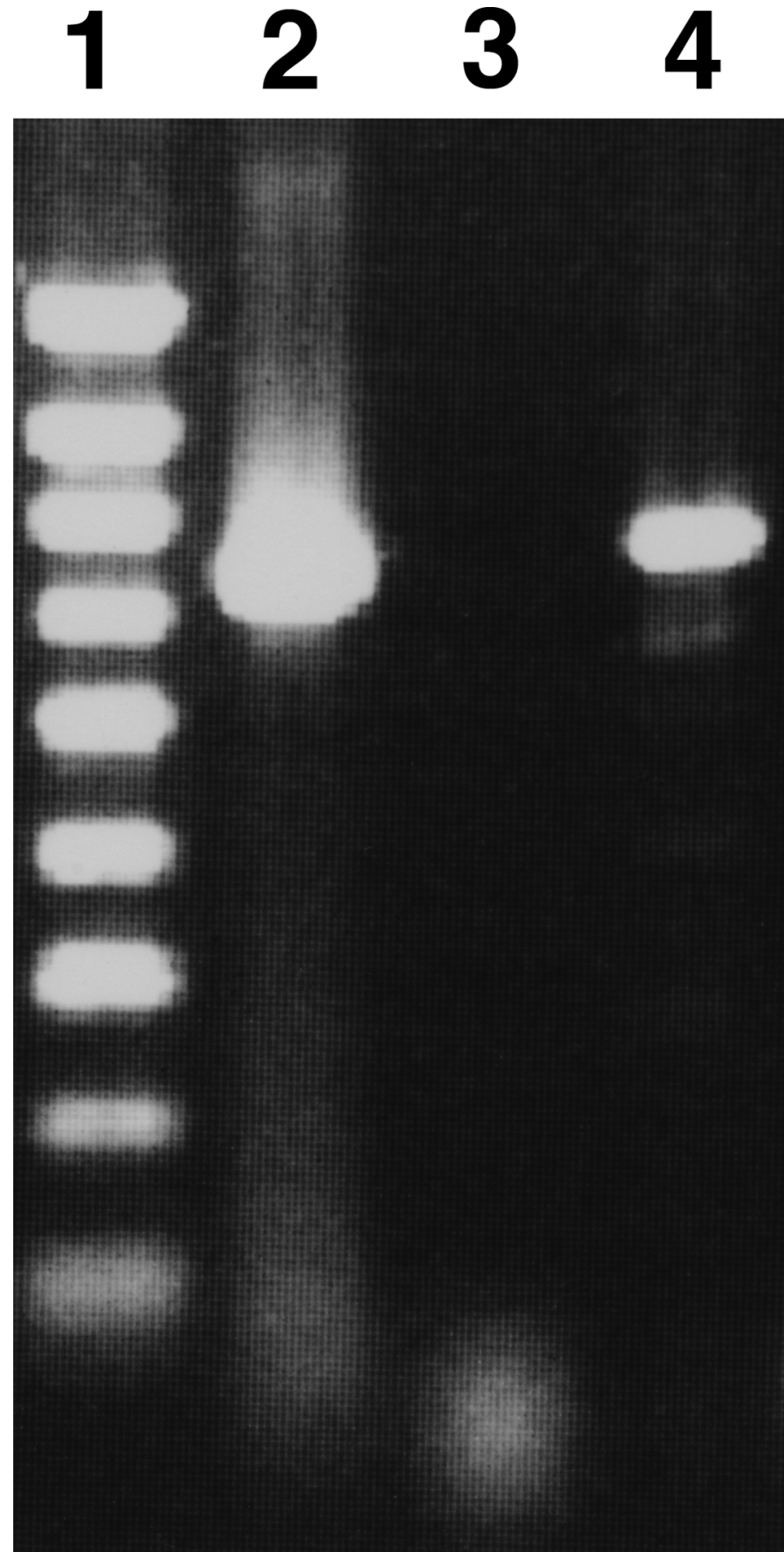

FIGURE 2. Analysis of PCR products by $1.5 \%$ agarose gel electrophoresis and ethidium bromide staining. Molecular weight markers (lane 1), $T$. foetus genomic DNA (lane 2), negative control (no DNA) for PCR reaction (lane 3), DNA extracted from the feces of a 3-mo-old dog with liquid diarrhea containing numerous trichomonads (lane 4).

rRNA gene. PCR using these primers amplified a 642-base-pair product that was sequenced and compared with existing sequences in the GenBank database (Fig. 2). Based on a comparison of each of 642 base-pair positions, the sequence shared $100 \%$ identity with the $18 \mathrm{~S}$ rRNA gene sequence of $T$. foetus (AF466749-51, AY055799, M81842).

In response to treatment with metronidazole, the microscopic appearance of trichomonads in the feces ceased and diarrhea gradually resolved. Over the following year, the dog had no additional bouts of diarrhea. Fifteen mo following diagnosis of $T$. foetus infection, feces were again sent to the authors' laboratory for analysis by $T$. foetus-specific single-tube nested PCR and amplicons were not observed.

Feces were obtained from 1 of 6, 4-wk-old German Shepherd puppies that were presented for acute onset of profuse liquid diarrhea, weight loss, and weakness. Diagnostic evaluation included a direct fecal smear examination, IFA for Giardia sp. antigen, and ELISA for Parvovirus antigen. The direct fecal smear examination revealed copious numbers of trichomonads with lesser numbers of Isospora canis ova. Feces were negative for Giardia sp. and Parvovirus antigen. Fenbendazole $(50 \mathrm{mg} /$ $\mathrm{kg}$ PO q $24 \mathrm{hr}$ for 5 days) was prescribed and feces were transported to the author's laboratory for analysis by PCR.

Amplicons were not generated from DNA extracted from canine feces using a single-tube nested PCR with $T$. foetus-specific primers (Gookin et al., 2002). Using PCR primers capable of amplifying both $T$. foetus and P. hominis 5.8S, ITS1, ITS2, and partial 18S and 28S rRNA genes (Levy et al., 2003), a 1,864-base-pair sequence was amplified (Fig. 3). The product was cloned, sequenced, and compared with existing sequences in the GenBank database. Based on a comparison of 1,475 basepair positions, the $18 \mathrm{~S}$ rRNA gene sequence shared $99.6 \%$ identity with the corresponding gene sequences of $P$. hominis (AF124609). Based on a comparison of 270-339 base-pair positions, the ITS-1, 5.8S, and ITS-2 rRNA gene sequences shared 99.4-99.8\% identity with the corresponding gene sequences of P. hominis (AF156964, AF342741, U86616, AY349187).

Profuse liquid diarrhea persisted and 4 of 6 pups died in the 4 days following their veterinary examination. For the remaining 2 pups, diarrhea gradually resolved and the dogs were reportedly healthy 6 mo later. The owner declined follow-up PCR to examine feces for persistence of $P$. hominis infection.

\section{DISCUSSION}

The present study is the first to establish, by means of rRNA gene sequence analysis, the identity of trichomonads infecting young dogs with diarrhea. These studies validate the longstanding assumption that trichomoniasis in young dogs is attributed to $P$. hominis; a conclusion previously based on morphological identity alone. Importantly, these studies additionally recognize that enteric trichomoniasis in the dog may also be associated with infection by $T$. foetus.

In dogs and other species, $P$. hominis is considered to be a commensal (Guilford and Strombeck, 1996; Barr, 1998; Jergens and Willard, 2000). On the basis of microscopy or culture, the prevalence of trichomonads in feces has ranged from 0 to $30 \%$ in reportedly healthy young dogs from Australia, Yugoslavia, and Japan (Simic, 1932a; Fukushima et al., 1990; Meloni et al., 1993), while in New Jersey $19.8 \%$ of 273 stray dogs with either diarrheic or fresh feces were identified with trichomonal infection (Burrows and Lillis, 1967).

The present report is consistent with prior studies in suggesting that trichomonads flourish in young dogs having diarrhea associated with coexisting intestinal infection. Previously reported ages of dogs with trichomoniasis and diarrhea have ranged from 7 wk to 6 mo (Bruce, 1941; O'Donnell, 1954; Narayana, 1976; Turnwald et al., 1988). In one study, puppies 


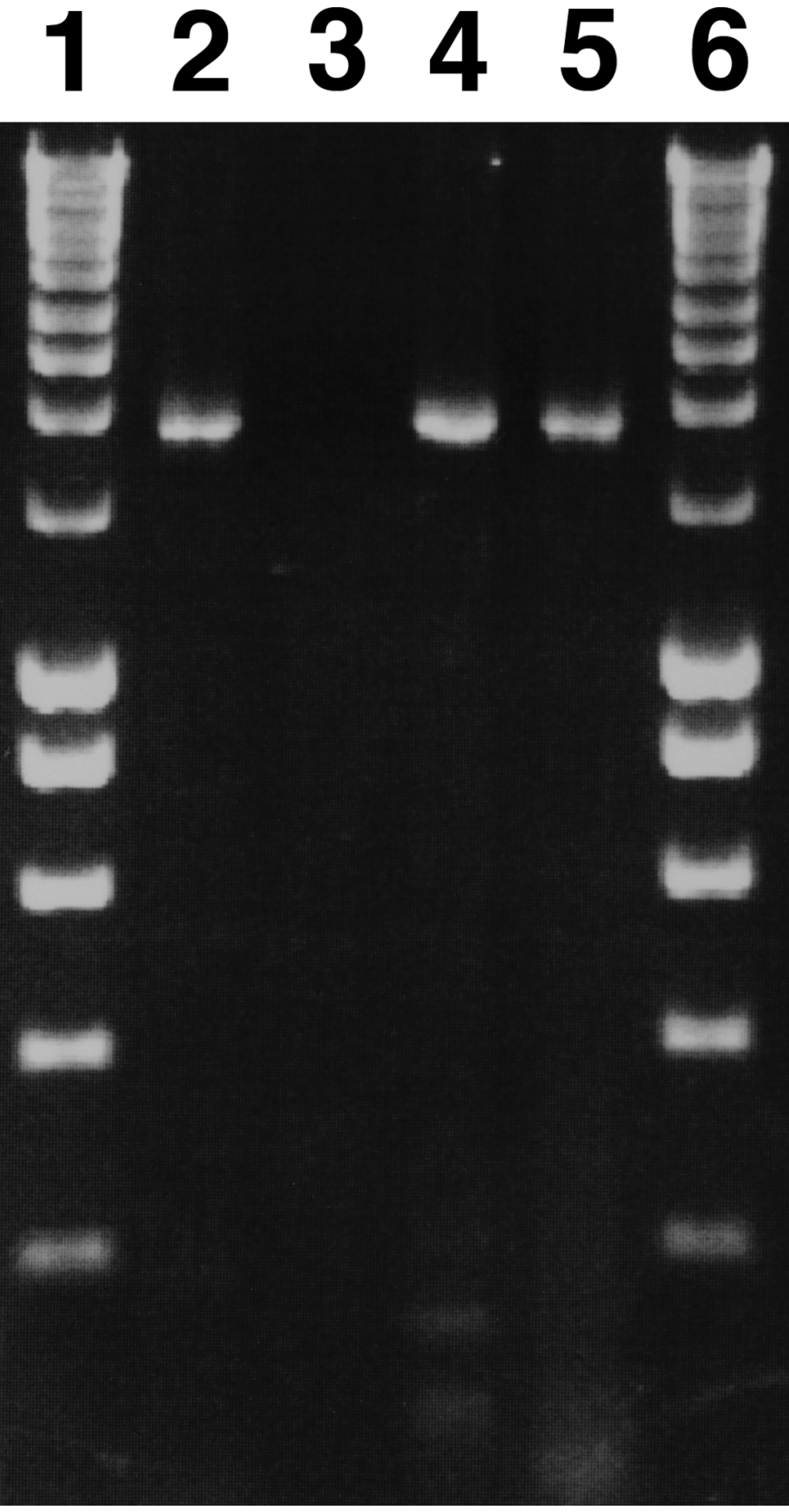

FIGURE 3. Analysis of PCR products by $1.5 \%$ gel electrophoresis and ethidium bromide staining. Molecular weight markers (lane 1), DNA extracted from feces of a German Shepherd puppy with liquid diarrhea containing numerous trichomonads (lane 2), negative control (no DNA) for PCR reaction (lane 3), T. foetus genomic DNA (lane 4), $P$. hominis genomic DNA (lane 5; ATCC 30098), and molecular weight markers (lane 6).

that were experimentally infected with canine trichomonads spontaneously cleared infection after 35 days and became resistant to reinfection thereafter (Simic, 1932b), suggesting the possibility of acquired immunity. In the same study, trichomonads could not be found in adult dogs, nor were adult dogs susceptible to experimental infection (Simic, 1932b). Coexisting intestinal infection is a consistent feature of canine trichomoniasis. Except for one instance (Narayana, 1976), all pub- lished cases have been confounded by cryptosporidiosis, ancylostomiasis, coccidiosis, giardiasis, canine distemper, or Toxocara canis infection (Bruce, 1941; O’Donnell, 1954; Turnwald et al., 1988). In the young dogs of this report, coccidiosis, giardiasis, or Clostridium spp., in addition to trichomonal infection, were also identified.

The present studies demonstrate that either $P$. hominis or $T$. foetus can be associated with diarrhea in young dogs. Both dogs had remarkably similar clinical presentations and the identity of the trichomonads could not be discerned based on their light microscopic appearance. Whether there is any prognostic significance to the identity of trichomonads or whether trichomoniasis contributed directly to diarrhea in the present cases in unknown.

Pentatrichomonas hominis is considered commensal and reportedly sensitive to treatment with metronidazole (Guilford and Strombeck, 1996; Barr, 1998; Jergens and Willard, 2000). In the present report, the pups infected with $P$. hominis were treated empirically with fenbendazole, an anthelminthic drug without efficacy against trichomoniasis or coccidiosis. As reported by their owner, diarrhea continued despite this treatment, resulting in the death of 4 of 6 pups, presumptively due to dehydration or other unidentified cause. In contrast, $T$. foetus is considered pathogenic and resistant to antimicrobial therapy (BonDurant, 1997; Gookin et al., 1999). In the dog with $T$. foetus infection, diarrhea persisted despite treatment and resolution of concurrent giardiasis. However, in contrast to $T$. foetus infections of other species, trichomoniasis and diarrhea gradually resolved coincident to treatment with metronidazole. This observation suggests that canine $T$. foetus may be susceptible to antiprotozoal therapy or that dogs have the capacity for spontaneous recovery. Whether $T$. foetus was a cause of diarrhea in the present case cannot be concluded from these observations alone. The origin of $T$. foetus infection in this dog remains unknown, insofar as the dog was born into a closed research colony and had no contact with cats or cattle.

\section{ACKNOWLEDGMENTS}

This study was funded by grants from Fort Dodge Animal Health and the National Institutes of Health (DK02868 and CA15704). The authors thank Linda Kidd, Christopher Mesher, and Dale Paley for technical assistance and Yumiko Kagawa and Karine Savary-Bataille for help with translation.

\section{LITERATURE CITED}

BARR, S. C. 1998. Enteric protozoal infections. In Infectious diseases of the dog and cat, C. E. Greene (ed.). W.B. Saunders Co., Philadelphia, Pennsylvania, 487 p.

BonDurant, R. H. 1997. Pathogenesis, diagnosis, and management of trichomoniasis in cattle. Veterinary Clinics of North America Food Animal Practice 13: 345-361.

BRUCE, K. L. 1941. Trichomoniasis in a puppy. Veterinary Medicine 36: 261 .

BurRows, R. B., AND W. G. LiLlis. 1967. Intestinal protozoan infections in dogs. Journal of the American Veterinary Medical Association 150: $880-883$.

FELLEISEN, R. S. 1999. Host-parasite interaction in bovine infection with Tritrichomonas foetus. Microbes and Infection 1: 807-816.

Fukushima, T., K. Mochizuki, H. Yamazaki, Y. Watanabe, S. YamaDa, T. Aoyama, Y. Sakurai, H. Mori, and M. Nakazawa. 1990. Pentatrichomonas hominis from beagle dogs-detection method, characteristics and route of infection. Jikken Dobutsu 39: 187-192. Gookin, J. L., A. J. Birkenheuer, E. B. Breitschwerdt, And M. G. 
LEVy. 2002. Single-tube nested PCR for detection of Tritrichomonas foetus in feline feces. Journal of Clinical Microbiology 40: 4126-4130.

, E. B. Breitschwerdt, M. G. Levy, R. B. Gager, And J. G. BENRUD. 1999. Diarrhea associated with trichomonosis in cats. Journal of the American Veterinary Medical Association 215: 1450-1454.

-, M. G. Levy, J. M. Law, M. G. Papich, M. F. Poore, and E. B. BREITSCHWERDT. 2001. Experimental infection of cats with Tritrichomonas foetus. American Journal of Veterinary Research 62: 1690-1697.

, S. M. Stebbins, E. Hunt, K. Burlone, M. Fulton, R. Hochel, M. TalaAt, M. Poore, And M. G. Levy. 2004. Prevalence of and risk factors for feline Tritrichomonas foetus and Giardia infection. Journal of Clinical Microbiology 42: 2707-2710.

Guilford, W. G., AND D. R. Strombeck 1996. Gastrointestinal tract infections, parasites, and toxicoses. In Strombeck's small animal gastroenterology, D. R. Strombeck (ed.). W.B. Saunders Co., Philadelphia, Pennsylvania, $427 \mathrm{p}$.

Jergens, A. E., AND M. D Willard. 2000. Diseases of the large intestine. In Textbook of veterinary internal medicine, S. J. Ettinger and E. C. Feldman (eds.). W.B. Saunders Co., Philadelphia, Pennsylvania, $1245 \mathrm{p}$.

Levy, M. G., J. L. Gookin, M. Poore, A. J. Birkenheuer, M. J. DyKSTRA, AND R. W. LITAKER. 2003. Tritrichomonas foetus and not
Pentatrichomonas hominis is the etiologic agent of feline trichomonal diarrhea. Journal of Parasitology 89: 99-104.

Meloni, B. P., R. C. Thompson, R. M. Hopkins, J. A. Reynoldson, AND M. GRACEY. 1993. The prevalence of Giardia and other intes tinal parasites in children, dogs and cats from aboriginal communities in the Kimberley. Medical Journal of Australia 158: $157-$ 159.

NARAyANA, G. S. 1976. Intestinal trichomoniasis in a pup-A case report. Indian Veterinary Journal 53: 477.

NiIyama, M., K. Too, Y. Maeda, R. Hata, And H. Shibata. 1972 Trichomonads isolated from a puppy with diarrhoea. Journal of the Japan Veterinary Medical Association 25: 592-595.

O'Donnell, F. A. 1954. Intestinal trichomoniasis in a dog. Veterinary Medicine 49: 390-391.

SimIC, T. 1932a. Etude biologique et experimentale du Trichomonas intestinalis, infectant spontanement l'homme, le chat et le chien. Annals of Parasitology 10: 209-224.

, 1932b. Etude complementaire de l'infection du chien par le Trichomonas d'origine humaine, canine et feline. Annals of Parasitology 10: 402-406.

Turnwald, G. H., O. Barta, H. W. Taylor, J. Kreeger, S. U. ColeMAN, AND S. S. POURCIAU. 1988. Cryptosporidiosis associated with immunosuppression attributable to distemper in a pup. Journal of the American Veterinary Medical Association 192: 79-81.

WENRICH, D. H. 1944. Morphology of the intestinal trichomonad flagellates in man and of similar forms in monkeys, cats, dogs, and rats. Journal of Morphology 74: 189-211. 